Binghamton University

The Open Repository @ Binghamton (The ORB)

The Society for Ancient Greek Philosophy Newsletter

$11-1970$

\title{
The Arguments in the Phaedo Concerning the Thesis that the Soul is a Harmonia
}

Christopher C.W. Taylor

Follow this and additional works at: https://orb.binghamton.edu/sagp

\section{Recommended Citation}

Taylor, Christopher C.W., "The Arguments in the Phaedo Concerning the Thesis that the Soul is a Harmonia" (1970). The Society for Ancient Greek Philosophy Newsletter. 80.

https://orb.binghamton.edu/sagp/80

This Article is brought to you for free and open access by The Open Repository @ Binghamton (The ORB). It has been accepted for inclusion in The Society for Ancient Greek Philosophy Newsletter by an authorized administrator of The Open Repository @ Binghamton (The ORB). For more information, please contact ORB@binghamton.edu. 
ccu Taylon
1970
$5 A G P$

Dec: 1970

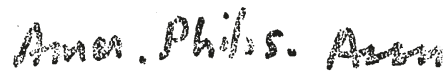

THE ARGUMENTS IN THE PHAEDO CONCERNING THE THESIS THAT THE SOUL IS A HARMONIA

At $85 e-86 d$ Simmias puts forward an argument to show that the soul cannot be immortal. The premisses of the aroument are, firstly, that the soul is a harmonia of the elements which compose the body, the hot, cold, wet, dry and so on (86b6-c2), and, secondly, that no harmonia can exist unless the elements of which it is a harmonia maintain the proper inter-relation. (This point is made in $85 \mathrm{e} 3-86 \mathrm{~b} 5$ with reference only to a particular case, the harmonia of a lyre, but is clearly to be taken generaliys) It follows that when the inter-relation of the bodlly elements has been dissolved by death, the soulharmonla cannot exist apart. This argument 1s presented in the dialogue as posing a major objection to the thesis of the immortality of the soul; those who had been convinced by Socrates' previous arguments are now thoroughiy dismayed (88c). It is, therefore, worth a certain consideration, particularly since the premiss that the soul is a harmonia expresses a philosopilcal doctrine whose sense is far from clear. Furthermore, the counter-arguments by which socrates claims to refute Simmias have produced considerable disagreement among commentators as to their interpretation, while questions may be ralsed as to their validity. I propose, then, first to ask what is the meaning of the thesis that the soul is a harmonia and secondly to examine Socrates' arguments agalnst simmias.

The ambiguity of the thesis that the soul is a harmonia emerges from consideration of the different shades of meaning which the word may have. Formed from the verb 'to flt together', It expresses the 1dea of things belng fitted together in an exact arrangement to make a properly-integrated whole, but particular uses express varlous aspects of the basic ldea. Thus the word sometimes means 'proportion', particulariy 1n contexts where elements are mingled in proportion, as when Empedocles describes painters mixing their colours 'm1xing them in poportion, some more and some less' (DK $31 \mathrm{~B} 23,1.4$ ), and sometimes 'arrangement' or 'organisation' (conveying the 1dea of the proper relation of parts), as when Heraclitus refers to the harmonia of opposite forces in a bow or a lyre (DK 22 B 51). Or agaln a harmonla may be 1dentical with a complex of parts in a certain order or arrangement; th1s 1s the sense in which the word can mean 'jolnt' or 'framework' (v. LSJ). Arlstotle's discussion of the soul-harmonia thesis at De An. A4 deals certalnly with the first two senses, and perhaps also with the third. In one sense a harmonia is the logos of a m1xture, 1.e. the rat1o or the elements which is capable of mathemat1cal expression. In another it is a combination (syrthesis) of physical objects, probably in the sense of the arrangement of a number of physical parts but perhaps also as the complex of those parts in that arrangement. There appears also to be a fourth sense of 
harmon1a wh1ch Ar1stotle overlooks, in wh1ch a harmonla is something causaliy dependent on but distinct fromaa certain disposition of materials, e.g. a melody is distinct from the strings which produce it, and equally from the tuning of the strings, though without strings there could be no tuning, and without tuning no melody. The word has this sense especialiy in musical contexts, meaning variously 'scale', 'mode' or generally 'mus1c' ( $v$. LSJ). Glven, then, that the elements In question are those whlch compose the human body, hot, cold, etc. (which are presumably thought of as different kinds of stuff), there appear to be four possible interpretations of the thesis that the soul is a harmonia of these elements:

a) The soul is identical with the etio or formula according to which the elements are combined to form the IIving man;

b) The soul is 1dentical with the mixture or combination of those elements according to that formula;

c) The soul is some entity produced by the combination of those elements according to that formula, but distinct al1ke from them and from the formula 1tself;

d) The soul is 1dentical with a state of the bodily elements, viz. the state of being comblned according to that formula.

It might be objected at this point that the third alternat1ve 1s 1liusory, since even where the harmonia is a scale or melody $1 t$ must be cons1dered 1dent1cal with a mixture of elements. Th1s seems 1mplausible on the assumption that the elements in question are strings or other physical objects which compose the instrument wh1ch produces the mus1c, but this assumption is m1staken. Just as the elements of a physical const1tution, e.g. the living human body, are the hot, the cold and so on, so the elements of a plece of music are the high and the low, which are concelved of as being mixed together in the proper proportions to give the right notes, elther in the sense that each note is thought of as consisting of so much of the high mixed with so much of the low, or in the sense that each mode or scale is produced by combining so nany high notes in fixed ratios with so many low notes. The elements, therefore, out of which a musical harmonia is formed are themselves musical ent1ties, the high and the low, and not the physical objects wh1ch produce the sounds. Th1s view of the elements of a musical harmonia is clearly expressed for instance in the pseudo-A ristotelean treat1se De Mundo, 396b $7 \mathrm{ff}$. (DK 22 B 10): Music makes a single harmonia out of different sounds by mixing together high and low, long and short notes'. On this view of a musical harmonla, then, the harmonia cannot be separated from 1ts elements, and so this view does not admit the third interpretation of the soul-harmonia as an independent alternative to the first two.

But while this view of the nature of musical harmonia appears to be the standard v1 of musical theory, and gives the most exact parallel to other kinds of harmonla, e.g. the 
formation of physical substances out of the elements, or the production of a certain temperature by mixing the hot and the cold, it is not the view of musical harmonia which Simmias uses to 1llustrate his thesis that the soul is a harmonia. For Simmias' presentation of his thesis involves positing a parallelism between two relations, of each of which the terms are a) a physical object and b) a non-physical entity causally dependent on that object. Thus corresponding to the incorporal soul we have the musical harmonia, which is 'invisible and Incorporeal and all-beautiful and divine' (85e 5-6), while corresponding to the physlcal body we have not the high and the low but the physical strings and pegs of the lyre, which can be broken apart and left lying around after the harmonia has vanished. It 1s true that simmias slightiy distorts the parallel when he says ( $85 \mathrm{~b} 5-\mathrm{c}$ 1) that the soul is a harmonia of the hot, cold, etc., in the body, since a more exact paraliel to the strings etc., of the lyre would seem to be provided by the limbs and organs of the body than by the1r microscopic elements. But the essential point is to contrast the incorporeal product with its physical cause, and 1n order to make this contrast it is unnecessary for Simmias clearly to distinguish the physical macroscopic parts of the body from their own elements, which are no doubt concelved of as minute but equaliy corporeal parts. The relation of musical harmonia to Its elements which Simmias is using cannot therefore be that between a scale or tune and the musical elements of high and low etc., but must be that between a musical instrument and some non-physical ent1ty produced by a certain state of the instrument.

Th1s, then, enables us 1mmediately to eliminate the second of our four suggested Interpretations of the soulharmonla thes1s, v1z. that the soul 1s 1dent1cal with the mixture or combination of the bodily elements according to a certalin rat1o or formula. For $1 t$ would be clearly absurd to make a sharp contrast between the physical elements and the non-physical harmonla if the latter just was 1dent1cal with the elements in a certain arrangement. One might as sensibly contrast the 1nvisible, incorporeal plum-pudding with the gross, earthy suet, ralsins, flour etc. which compose 1t. Th1s still leaves us with three alternatives, that the relation of the soul to the body is a) that of the ratio of the tuned strings to the strings themselves, or $b$ ) that of the music produced by the instrument to the instrument itself, or c) that of the state of being in tune to the strings.

There seems no conclusive evidence from the dialogue which alternative Plato had in mind, or indeed whether he had clearly distingulshed the three. Varlous phrases give some hints, but these are conflicting and inconclusive. Thus for instance the description of musical harmonla as 'all-beaut1 ful and divine' might seem most readily applicable to the music produced by the instrument; but when we reflect that the speaker is a pupil of the Pythagorean Philalaos, and might therefore 
be expected to have a l1vely reverence for numbers as the source of all things, this argument seems to have little force as between alternatives a) and b). Rather stronger is the argument from Simmias' statement at 92d 2 that the soul-harmonia doctrine is accepted by most people; surely, 1t may be argued, this ind1cates that the soul is something distinct from a mathemat1cal ratio, since such an obscure theory can never have been held by the majority of ordinary people. On the other hand, the view that the soul is something non-physical, which is yet dependent on a certain state of the body, so that when that state $1 \mathrm{~s}$ disrupted the soul is disslpated, might seem to be a belief quite congenial to common sense. But against this we have the comparison of the soul at $86 \mathrm{c} 6-7$ to 'harmonial in sounds and in all the works of the craftsmen'. 'All the works of the craftsmen' must include statuary and palnting, and probably carpentry and house-bullding as well. Where, in the cases of the products of these arts, are we to lilok for the non-physical product of the physical elements? Surely in the harmony or proportion of the constituent parts, as exemplified by different amounts of differently-coloured paints, or by the relations between the dimensions of various parts of a statue or a plece of furniture. It would be too fantasi1c to suggest that to every well-made table there corresponds a non-physical ent1ty which is related to the dispositions of 1 ts parts as the nonphysical soul is to the disposition of the bodily elements. Th1s comparison, then, tends in the opposite direction from the remark at $92 \mathrm{~d} 2$ that most people accept the soul-harmonia thesis. Further difficulty is created by the description of the soul at $86 \mathrm{~b} 9$ as a mixture (krasis) of the bod1ly elements. The word kras1s, wh1ch is regularly used as a synonym for harmonla (e.g. Ar. De An. 408a 30-31), commonly occurs, l1ke the Engl1sh 'm1xture' 1 in contexts wh1ch leave 1 t open whether the word refers to the state of being mixed together or to the compound of olements which are mixed up. We have seen that the second alternative is clearly unacceptable, but what about the first? Can Plato mean that the soul is 1dentical nelther with a ratio nor with any product of a rat1o, but rather with a certain state of the body, viz.the state in which he elements of the body are in a certain rat1o? Wh1le on the one hand this would glve a falr account of the compar1son of the soul with works of art, on the other hand 1 t fits rather 111 with the sharp contrast between the invisible, divine musical. harmonia and the physical instrument, while again It mjght well seem very dublous that most people belleve that the soul is nothing other than a bod1ly state. There appear, then, to be hints in the text of the dialogue of support for all three possible interpretations of the soul-harmosia thesis, a) that the soul is 1dentical with a ratio of the bodily elements, b) that 1 t is 1dent1cal with some non-physical product of that rat1o and c) that $1 t$ is 1dentical with the state of being in that ratio. It might thus appear that Plato has ralled to distingulsh these alternatives; before leaving this question, however, we should look at some evidence from other sources, to see whether they throw any light on plato's meanIng. 
First of all there is the fact already mentioned, that in his discussion of the thesis in De An. A4 Aristotile ignores the possibilities that on this theory the soul might be a non-physical entity causaliy dependent on the ratio of bodily elements or that it might be a bodily state, while explicitiy mentioning the possibility of 1ts belng 1dent1cal with that rat1o, or with a spatial arrangement of parts. Further, not only does Aristotle not give these as possible interpretations of the thesis, but he appears to introduce the former as an alternative view of the soul which would be unacceptable to one who held the harmonia theory. He produces objectors first to the suggestion that the soul is a combination of liabs and then to the suggestion that it is the ratio of the mixture of elements, objecting to the latter on the ground that since there is a different mixture for flesh, bones, etc., there would have to be a number of souls in each body. He then adds (408a 20-2I) 'Is it the ratio which is the soul, or $1 \mathrm{~s}$ 1t rather something separate which comes to be in the parts of the body?" The implication 1s that Aristotle is suggesting a more plausible alternative theory, not giving an interpretation which a supporter of the theory might be inclined to accept as expressing his meaning. But in order to contend on the strength of this that the thesis of the phaedo 1s definitely to be interpreted as identifying the soul. with a rat1o.or arrangement we must be certain that both Arlstotle and the phllosophers whom he is discussing had made all these crucial distinctions. Even in the case of Arlstotle himself this assumption appears questionable; for instance, at $408 \mathrm{a} 1-3$ he says that 1 t $1 \mathrm{~s}$ more plausible to call health or other physical excellences harmonial than to say that the soul is a harmonia; does he mean by this that 1t would be plausible to 1 dentify health with some ratio or arrangement of elements, or rather with some state, say the capac1ty for various activities, which supervenes upon the possession of sucr a ratio, or even with the state 1tself of having one's elements in this ratio? When one recalls the difficulties Arlstotle has over the question whether pleasure is 1dent1cal with the activities which one enfoys or is something supervening upon them, one might well hesitate before pronouncing on Arlstotle's exact meaning here. And $1 f$ this doubt arises in the case of Aristotle, how can it be avolded when one attempts to reconstruct the views of earlier philosophers?. Arlstotle may well be concentrating on what he considers to be the central sense of the word harmonia, lgnoring, perhaps unconsclously, the confusions which run through: the theory he is criticlsing. Since we have seen ground for thinking that such confusions are present in the Phaedo passage, 1t appears unfustified to take aristotle giving the undisputed sense of that passage, to which he does not in any case refer explicitisy

One might hope to throw some light on this question by considering the origins of the theory; but here too it seems Imposible to reach any positive conclusions. Ne1ther Aristotle nor any of the speakers in the Phaedo attributes it to any named philosopher, but since simmias says that 'we' hold the soul to be a harmonia $(86 \mathrm{~b} 6-7)$, and Echecrates that he has always been very Impressed w1th that thesis (88d 3-4), it would 
be natural to assume that $1 t$ was current in the Pythagorean c1rcle to which they belonged. Though they are described as pup1ls of Ph1lolaos (6Id-e; D.L. v111, 46), the theory 1tself is not ascribed to h1m by any writer earlier than Macroblus ( $4-5$ cent. A.D.), who says that Pythagoras and Philolaos held that the soul is a harmonia (DK $44 \mathrm{~A} \mathrm{23)}$ ). It is not clear how much reliance can be put on this testimony, since there is obviously a possibility that 1t may derive ultimately from this very passage of the Phaedo. But whatever may be the truth about that, it is highly unlikely that Philolaos' view of the soul can be reconclled with the harmonla theory as expounded by S1mmias. For at $61 a-62 b$ it 1s 1mplied that Philolaos taught that sulc1de was wrong on the ground that the soul 1s put by the gods in the body as a prison for a set time, and must not seek to escape before the t1me of Its release, but that a philosopher w1ll welcome death, presumably because his soul will have a better existence in separation from the body. This is supported by a quotation from Philolaos given by Clement of Alexandria (DK 44 B 14) 'the soul 1s yoked to the body and as 1t were burled in this tomb as a punishment'. The conclusion from this 1s plain, that unlike his pup1ls who take part in the dialogue, Ph1lolaos belleved that the soul exists independently of the body. It is not 1mpossible that he may have held some version of the theory, in which the soul was a non-physical ent1ty whose association w1th the body depended on the maintalnance of the proper bodliy rat1o, but the divergence from the view expressed by Simmlas is so great that it is obviously frultiess to attempt to interpret the latter in such a way as to assimilate 1t to some conjectural reconstruction of Philolaos' view.

I conclude, then, that not only is there no evidence that the soul-harmonia thesis defin1tely 1dent1ries the soul e1ther with a ratio of 1 ts elements or with the state of being in that ratio or with some ent1ty dependent on the possession of that rat1o, but that we can best account for what $1 \mathrm{~s}$ sald in the dialogue on the assumption that Plato did not clearly distinguish the three possib1lities. Nor 1s this particularly surprising; for in the first place the distinction is a very fine one between the soul's actually being a rat1o and 1ts being the state of having one's elements in a rat1o, since in either case having a soul w1ll be ldentical with having one's elements in a rat1o. It is possible to be dear about the distinction only if one clearly distinghishes purely mathemat1cal ent1ties such as numbers from states of physlcal objects which can be described in mathematical terms. Fallure to make this distinct1on was the ground of one of Arlstotle's criticlsms of the Pythagoreans (Met. A8, 989b29-990a32), wh1le we have seen that the presentation of the thesis by S1mmias in the dialogue $1 \mathrm{~s}$ similarly uncleax. Wh1le the distinction between the soul as a ratio and as an entity supervening on the possession of a ratio is more obvious, Arlstotle's example of health which we have already noticed indicates that that distinction too may 
be easy to overlook. In consldering Plato's arcuments agalnst the thesls we shall therefore have to regard them as concerned with a thesis which contains in an undifferentiated form the three alternative senses which we have considered.

Socrates' flrst argument against the thesis requires little comment. He points out that it is 1nconsistent with the doctrine, which was earlier accepted, that all knowledge is in fact recollection of what the soul had learnt in a previous existence when 1t was not assoclated with the body. No haminonla can exist unless the elements of which it is a harmonla are already in existence, and hence $1 f$ the soul is a harmonia of the bod1ly elements it cannot have had a previous non-bodily existence (9le-92e). This argument is valid against any interpretation of the harmonia thesis; obviously a bodily state cannot exist unless some body exists of which 1 t 1 s the state, and equally obviously a nonphysical ent1ty causally dependent on a ratio of bodily elements cannot exist before those elements have been oombined in that rat10. A defander of the thesis might, however, argue that it is not cogent against the ldentiflcation of the soul with the mathemat1cal rat1o 1tself. For a rat1o, belng a ilmeless mathemat1cal ent1ty, cannot 1tself be sald to come 1nto existence whenever it is embodied in some particular material. Since it exists equally at all time, it may truly be sald to have existed before a certaln body came into belng, and hence the argument from recollection does not refute this version of the thesis. This defence is not, however, adopted by Simmias, who agrees that his thesis is inconsistent with the doctrine that all knowledge is recollection. Nor is it difflcult to see why. For it is possible to defend the soul-harmonla against this argument only at the cost of making 1t a universal; if a certain set of elements combine in the ratio $3 / 4$, then inceed that ratio exlsted before the combination of the elements, but the thing that existed was the ratio $3 / 4,1 . e .$, the very same rat1o which 1s exemplified whenever three units are related to four units. Thus anyone who held this theory would have to admit that it was logically possible for many things to have the same soul, includIng things which would generally be reckoned inanimate, e.g., geometrical diagrams, since there is no reason why the same ratio which is embodled in a particular human being and is his soul might not also hold between certain lines and angles. It is not, of course, 1mpossible that anyone may have believed something like this; 1t might, for instance, provide a theory to account for transmigration. Empedocles would on this view have been a bush and a fish because one and the same rat1o was embodied in bush, flsh and Empedocles, 1.e., they all had the same soul. Simmias, however, will have none of this; if his version of the theory is interpreted as making the soul a mathemat1cal ent1ty, it must be such an ent1ty 1ndividuated by being embodied in these bodily elements. As such it clearly cannot exist independently of the elements by reference to which it is individuated, any more than Socrates' helght can exist independently of Socrates, though in the sense in which Socrates' helght is a universal, say four cubits, that length may be sald always to have existed, or rather never to have come into ixistence, whether or not socrates exists. 
Th1s way of looking at the soul-harmonla has the advantage of preserving as a necessary truth that d1fferent persons have numerlcally different souls, whereas on the other interpretation two contemporaneous persons might discover as the result of physiological investigation that they had the same soul. It leaves the thesis open, however, to attack on the grounds of Inconsistency with the doctrine of knowledge as recollect1on; whether one considers $1 t$ adequately refuted on those grounds will naturally depend on the strength of one's conviction in the soul's pre-existence.

The remalning arguments are more problematical, in that commentators have disagreed not so much as to the1r conclusiveness, but rather on the question of how many arguments socrates employs, and Just what these arguments are.. L1ke M1ss H1cken In C.Q. 1954 , pp. 16-22 and Bluck in his commentary, I discern two arguments, as opposed, for instance, to the four specffled by Philoponus in his commentary on Arlstotle's De An. A4.1 These arguments are not, however, presented consecutively; at 92e 4-93alo socrates gives a set of premisses (A) which are not Immediately used in the argument. Instead, at 93all-12 he begins a new argument by formulating a princlple which is to some extent independent of the set of premisses A. Th1s argument continues to 1ts conclusion at 9a12-b2; for convenience this whole argument may be called $B$. Then at 9404 Socrates returns to the set of premisses A, wh1ch he uses to construct the second argument, which we may call $A^{l}$, whose conclusion 1 s reached at 95a.2. While I shall deal first with argument $B$, it is necessary first to look at premisses $A$, in order to determine the relation they have to the principle with which Socrates beglns B.2

A beglns with the acceptance by S1mmlas of the proposition that the qualities of a harmonia are determined by those of 1 ts elements (92e4@93a2; let this be labelled al). We then have three succeslve applications of this princlple, first to all activitles and passivities of the harmonia (93a4-5; al.1) and then to a particular activity and some particular passivities which are ruled out by the princlple. In virtue of the princlple 1t is 1mpossible for a harmonia to lead or control its elements, but 1t must rather be controlled by them (93a6-7; al.1I), and $1 t$ is $1 \mathrm{mpossible}$ for $1 t$ to be affected in any way contrary to that which 1ts elements determine (93a8-9; al.12). It is al.11 and al.12 which provide the premisses for argument $A^{1}$. At 93all-12 we have the principle whlch marks the beginning of argument B: 'Well, now, doesn't every harmonla have to be the k1nd of harmonia which corresponds to the way that it is attuned (or arranged)! (bI). It is not easy to find a translation which $1 \mathrm{~s}$ both exact and comprehensible but the next sentence, giving an application of the princlple, makes falrly clear what is meant; if a Harmonla is more attuned, then it is more (oI) a harmonla, and $\overline{1 f 1 t 1 \mathrm{~s}}$ less attuned it is less (of)

I The grounds for rejecting Ph1loponus' interpretation, which is followed, not without incoherence, by Archer-Hind and Hackforth, are cogently stated by M1ss Hfoken, pp. 17-8.

2 See Append1x 
a haromia $(93 a 14-b 2 ; b 1.1)$. The sense of bl 1tself can then best be expressea formally, as lollows, that where ' $\varnothing$ ' stands for an adjectfve whlch can apply to aharmonla, and where 'oly'. is the adverb formed rrom' $\phi^{\prime}$, then for all $x$, if $x$ is a harmonLa, If $x$ is attured or arranged $\phi 1 y, x$ is a $\phi$ harmonla. While this certainly goes beyond-anything that is saidin $A$, it seems an extremev1ew of Miss Hicken that Socrates here begins 'an ent1rely new set of admissions'; rather we might say that this 'formal' account of the dependence of the harmonia on what gives rise to it is least suggested by what has been said in $A$. The difference is that whereas there we were concerned with the dependence of the harmoniar on the elements, now we are concerned with 1ts dependence on the state or process of belng arranged ar attuned. Argument $B$ proceeds by way of two. further premisses, b2, that no soul is more or less (OP) \& soul than any other $(93 \mathrm{~b} 4-7)$ and b3, that a good soul is in tune and a bad soul out of tune (93b8-c10). Ne1ther of these premisses is felt to require any Justification or explanation; the sense of the latter 1s clearly that the good man 1 s not a prey to the conflicting desires and impulses which are the mark of the bad man, but has all his wants properly under control with a view to the attainment of the right ends. We now come to one of the most problematical passages in the argument: at 93dl-5 Socrates says that premiss b2 is the same as the proposition (b2.I) that no harmonia is more or less (of) a harmonla than any other, and Simmias agrees. Of course b2 is not as 1t stands equivalent to this, and the question is what additional assumptions Plato must have used in order to produce what he considered a val1d equivalence. Clearly we cannot arrive at such an equivalence simply by making the most obvious assumption, v1z. the assumption under examination in this argument, that the soul is a harmonia, since taken together with b2 that would still allowthat some harmonlal might be more or less harmonlal than others. But did Plato see that? I am inclined to think that he did not, but rather assumIng that the soul is a hamonla, took th1s to mean that everything which is true of soul is also true of harmonia (using thease terms in the unquantifled style familiar from Aristotie). In effect this is to confuse implication with equivalence, which seems a not unlikely error for plato to commit at this stage in his phllosophical development, since it is only in the Sophist that he clearly distinguishes predication from ident1ty.

The standard modern interpretation of this sentence, adopted by Archer-Hind, Bluck, Hackforth and Miss Hicken (but not by Burnet) differs rrom the above in tak1ng socrates to be assert-ing not a general proposition about all harmonla1, but a spec1ifc proposition about the sort of harmonlal, that souls are, viz. that no soul-harmonia is more or less or a harmonla than any other. As this requires an admittedly unnatural reading of the text as 1 t stands, many scholars (see Hackforth's note, p. I16) have suggested removing the word harmonlas from d4, thus making the sentence read 'And this (namely the admission that no soul is more or less ( $O F$ ) a soul than any other) 1s the admission that no (soul) is more or less a harmonla than any other.' But since this emendation lacks any manuscrlpt authority, and destroys what looks like a very emphat1c and dellberate paralle ismin 
of sentence construction, $1 t$ is worth asking whether there are cogent grounds elther for emending the text, or for reading the recelved text in other than 1ts natural sense. The strangest ground appears to be that urged e.g. by M1ss H1cken, that since the argument is to depend on the assumption that some harmonla1 (In particular, goodness) admit of degrees, 1t would be flatIy inconsistent if Plato also used the assumption that no harmonia admits of degrees. I doubt the cogency of this argument, wh1ch seems to me to depend on a confusion over the notion of 'degrees of attunement'. For the thes 1s that some harmonla1 (e.g. goodness) admit or degrees comes to this, that some things, e.g. the parts of the soul, may be so arranged as to approxlmate more or less closely to spme norm wh1ch represents the perfect arrangement of those things. - But that is in no way in compat1ble with the thesls wh1ch I take Plato to be asserting at 93dl-5, viz. that if what a thing is is a harmonia, it can't be more or less a harmonla than anything else. This amounts to an extension of the trulsm 'Everything $1 \mathrm{~s}$ what $1 \mathrm{t}$ 1s', and applies equally to degrees of harmonia, in the sense just expla1ned. Every inter-relation of parts of the soul, at whatever remove from the norm, is an inter-relation of parts. There is, then, no general incompatib1l1ty between the thesis 'No harmonis is more or less a harmonla than any other' and 'Some things are more attuned ( 1 n Platon 1 c terms 'partake more of harmonia') than others'. Plato, however, thinks contradiction arises 1f one tries to say that one harmonia is more attuned than some other: that he is wrong even in this restricted thesis will be seen once the argument is viewed as a whole. The next step (93d6-8) is that something which is ne1ther more nor less (of) a harmonia is ne1ther more or less attuned: this follows directly by contraposition from bl.l, and may hence be called bl.2. Another problemat1c sentence follows (d9-10): 'And does that wh1ch $1 \mathrm{~s}$ ne1ther more nor less attuned partake more or less of attunement, or to just the same extent? To the same extent.' At first sight 1t might appear that this is the converse of the proposition stated 1mmediately before (and $1 t$ is so taken by Miss Hicken): But, firstly, in contrast to the previous sentence, where the subject 1s 'that which is ne1ther more nor less a harmon1a', the predicate of $39-1 \overline{0}$ is 'partakes of ( $1 . e$. Is characterlsed by) harmonia more or less'. One might indeed see here a further confusion of predication and identity, but the shift in terminology is presumably intended to indicate that a new point is being made. Secondly, if d9-10 is 1nterpreted as 'Something which is neither more nor

1 Another sense in which harmonial admit of degrees is erempliried by temperature, where the inter-relation of hot and caldimakes up a continuous scale, but that is irrelevant for the purposes of this discussion, since there is no norm of heat or cold, and so no sense in which one temperature might be thought to be more or less arranged than another. 
less attuned is ne1ther more nor less a harmonia, 'it has no subsequent role in the argument, whereas if 1 t 1 s read 'Something which is relther more nor less attuned is ne1ther more nor less harmonious', we have a stralght forward argument of a syliogistic form, as will be seen below.

Socrates next concludes (93al2-e2) that no soul is more or less attuned or arranged than any other, glving as premisses b2 and apparently bl.2. But clearly some additional premisses are required, v1z. the understood assumption that the soul is a harmon1a and b2.1, that no harmonia is more or less a harmonia than any other. In fact the conclusion follows from these two together with bl.2, without depending on b2, but since Plato regarded b2 and $\mathrm{b} 2.1$ as equivalent he would not have noticed the redundancy. From this point on the argument proceeds straightforwardy. From b5 and b6 it follows syllogistically that no soul is more or less hamonious than any other (e4-5) and hence, by b3 that no soul is better or worse than any other. It is agreed ( $94 a 12-b 3)$ that this conclusion is absurd, and hence one of the premisses from which 1t is derived must be false; obviously, the one to be rejected is the assumption that the soul is a harmonia.

It appears, therefore that in $B$ we have a single argument which 1s, despite some obscurities clear in 1ts main lines and (perhaps not so clearly) fallaclous. The flaw is not simply in the fallacious equivalence of b2 and b2.l, since one might patch this up by 1ntroducing b2.1 as an independent assumption; 1t is perfectly plausible to suggest that, where of is a predicate saylng what kind of this its subject is $1 f^{\circ} A$ and $B$ are both os, A can't be more (of) a $\emptyset$ than B. A more serious flaw $1 \mathrm{~s}$ that the kind of harmonia whose presence or absence makes a soul good or bad is not the same kind as that which makes a soul to be a soul; the latter 1s a harmonia of bodily elements, whereas the former is a harmonia of parts of the soul, or of desires and emotions, or slmilar psych1cal ent1ties. Thus when Plato argues that because no soul can be more of a soul-harmonia than any other therefore no soul can have more 'virtue'-harmonla than any other, he is guilty of a fallacy of equivocation. An 1llustration should make the polnt clear. One might reasonably say that some plece of music was a harmonla in that $1 t$ was produced by strings playlng together in certain ratios, and yet that It lacked harmonia in that some of the strings were out of tune with ore another. I We may thus reject the opinion of most commentators (most v1gorously expressed by M1ss H1cken) that to say that something which is a harmonla e1ther has or lacks a harmonia is as absurd as to say that ablow is e1ther vulnerable or 1nvulnerable or that a length elther has or lacks a length. And In rejecting this oplnion we reject Plato's argument and derend the propriety of holding both that that the soul 1 s an entity which depends on some relation of bod1ly elements and that 1t 1 tself contalns parts or faculties which can be better or worse integrated with one another. Put like that, these propositions both seem reasonable enough, and $1 t$ is perhaps surprising to notice the eagerness w1th which writers on Plato have insisted that one must abandon one or the other. 
Argument $A^{l}$ begins 1mmediately. It is agreed at $94 \mathrm{~b} 4-\mathrm{cl}$ that in a sensible man the soul controls and opposes bodily inclinations such as hunger and thirst. Socrates now (94c3-36) recalls premisses $a 1.11$ and al.12, to the efrect that a harmonia can never control or be opposed to 1ts elements. Hence, (943895a2) the soul cannot be a harmonia. Th1s concludes the discussion of the thesis, and socrates goes on to deal with the separate objection raised by Kebes.

Despite 1 ts neatness, this argument too has certain susp1clous features. For $1 t$ is not clear that the elements of which the soul is sald to be a harmonla in the conclusion are the same elements as those wh1ch are referred to in the premisses. G1ven the earlier account of the theory by S1mmias, 1t. would be most natural to take the premisses to say that the activity of the soul is determined by the relations of the bodily elements such as the hot and the cold, so that, for instance, a certain m1 ture of hot to cold will produce anger in the soul, or a certain mixture of wet to dry will produce a desire for a drink. But in the conclusion Socrates treats such events as belng angry or wanting a drink as themselves being the physical elements of which the soul is a harmonia, and insists on the incompatiblity of the premisses with the view that the soul opposes these events, in the sense that the reason often brings such desires under control. But clearly, there need be no such incompatib1lity. All that a defender of the harmonla thesis need say is that in the case of such a conflict of reason and desire we see, not the soul-harmonla opposing and controlling its elements, but rather one part of the soul-harmonla opposing and controlling another. And he mlght add for good measure that of course the controli1ng part is equally determined by some disposition of the bodily elements. In effect this would be to replace the soul-body dual1sm of the Phaedo w1th an account akin to the view of the divided soul in the Republic and Phaedrus, with the addition of a thesis of physicalistic determinism of the functioning of all parts of the soul. It is no doubt Plato's intention to resist this determinism, and to insist that the soul, or rather the rational element in 1t, is an autonomous agent, but his arguments in the Phaedo seem somewhat too strong If this is their main intention, since they are directed not specifically against the view that the soul is a harmonla of bodily elements, but agalnst the view that $1 t$ is a harmonia of any sort. If they were successful, they would indeed refute physicalistic determinism, but at the cost of refuting any such theory as that of the Republ1c. For there seems to be a perfectly good sense in which the tripartite soul of the Republic may be called a harmonla, since it is a composite entity made up of parts whose relations affect its functioning as a whole." So if the arguments in the Phaedo were conclusive, the whole psychology and corresponding political organisation of the Rerablic are based on a theory which Plato had already (assuming the priority

1 This point 18 made by Confrord, $\underline{\text {.QQ. }} .1922$ p. 149, and by Hackforth, Plato's Phaedo, p. 120. 
of the Phaedo) refuted. This difflculty does not seem to have occurred to those who so enthusiast1cally endorse Socrates' arguments here. In fact, the arguments of the phaedo are not declsive against any version of the harmonia thesis. Their main importance lies in making explicit the 1ncompatiblilty of physical determinism with a view of the non-physical soul as an autonomous agent, but this is far from showing that the deterministic thesis is false. 
f al The qualities of a harmonia are determined by those 92e4-93ac of 1 ts elements. $P($ remiss $)$

al al.1 The activity or passivity of a harmonla is determined by the activity or passivity of 1ts elements. $24-5$ (from al)

al al.11 It 1s 1mpossible for a harmonia to control 1ts elements. (from al.1) $a 6=7$

al a.12 It is 1mpossible for a harmonia to be affected contrary to its elements.

(from al.l)

bl A harmonia must be as $1 t$ is attuned.

P $\quad$ a $11-12$

bl bll If a harmonia is more or less attuned it 1 s more or less a harmonia (from bl)

b2 No soul is more or less a soul than any other. P b4-7

b3 A good soul possesses harmony, a bad sould disharmony.

b $8-c 10$

b2 b2.1

No harmonia is more or less a harmonla than any other. (from b2 by equivalence: Inval1d)

bl bl.2 Something which is ne1ther more nor less a harmonia is 1ther more nor less attuned.

(from bl.l by contraposition)

b4 (The soul is a harmonia).

b5 Something which is nelther more nor less attuned possesses ne1ther more nor less harmony.

d $1-5$

$d 6-8$ al $4-b 2$

$\mathrm{b} 1, \mathrm{~b} 2$,

b4
b6 No soul 1s more or less attuned than any other.
(b1.2, b2.1, b4)

$1 \mathrm{mp} 11 \mathrm{c} 1 \mathrm{t}$

d $9-10$

d $12-e 2$

bil, b2, $b 4, b 5$

b7 No soul possesses more or less harmony than any other.

e $4-5$

b1-5 b8 No soul 1s better or worse thany any other. (b3, b6)

$\mathrm{b} 1-3$

b 9

The soul hot a harmonia.

b5

(Prom b4, b8 by reduct10 ad absurdum)

$A^{1}$

a2

The soul controls and opposes bodily inclinations.P

b $4-c 1$

al

Re-statement of al.ll and al.12.

c $3-7$

al, a2

The soul 1s not a harmonia.

c8-95a2 